\title{
A EXPERIÊNCIA NORTE-AMERICANA COM AS RESTRIÇÕES LEGISLATIVAS AO MANEJO DAS AÇÕES COLETIVAS DE CONSUMO E O SURGIMENTO DA AÇÃO COLETIVA PASSIVA (DEFENDANT CLASS ACTION)
}

\author{
THE AMERICAN EXPERIENCE WITH LEGISLATIVE RESTRICTIONS TO \\ COLLECTIVE ACTIONS CONSUMPTION MANAGEMENT AND THE \\ EMERGENCE OF THE DEFENDANT CLASS ACTION
}

\section{${ }^{1}$ Dennis Verbicaro}

\section{RESUMO}

O artigo propõe-se a identificar as razões que levaram às alterações legislativas e à consequente restrição no manuseio das ações coletivas nos Estados Unidos, com especial atenção ao surgimento da ação coletiva passiva (Defendant Class Action) e de que modo seria possível antecipar cenários e evitar a reprodução desse ideário conservador no Brasil, blindando a posição jurídica do consumidor, sobretudo quando identificado no plano transindividual como categoria econômica e juridicamente fragilizada.

Palavras-chave: Direito do Consumidor, Tutela Processual, Ações de Classe, Ação Coletiva Passiva-Direito Comparado.

\begin{abstract}
The article proposes to identify the reasons that led to legislative changes and the consequent restriction on the handling of class actions in the United States, with special attention to the appearance of the defendant class action (Defendant Class Action) and how it would be possible to anticipate scenarios and prevent reproduction of conservative ideology in Brazil, armoring the legal position of the consumer, especially when identified in the plan as transindividual economically and legally fragile category.
\end{abstract}

Keywords: Consumer Law, Procedural Protection, Class Actions, Defendant Class Action, Comparative Law.

\footnotetext{
${ }^{1}$ Doutor em Direito do Consumidor pela Universidad de Salamanca - USAL, Salamanca (Espanha). Professor da Graduação e do Mestrado em Direito pela Universidade Federal do Pará - UFPA, Pará (Brasil). E-mail: dennis@gavl.com.br
} 


\section{INTRODUÇÃO}

Não se pode negar que as grandes vantagens da defesa processual coletiva do consumidor, forjadas em uma base normativa solidária, trouxeram grandes benefícios para a sociedade brasileira.

A Lei 8.078/90 (Código de Defesa do Consumidor - CDC) aprimorou o alcance da própria Lei 7.347/85 (Lei da Ação Civil Pública - LACP), trazendo um capítulo próprio para o reconhecimento plural de direitos a partir de uma perspectiva transindividual, mesmo que preservasse a autonomia dos interesses individuais subjetivos, por meio do right do opt in/out, nos artigos 103 , parágrafos $1^{\circ}, 2^{\circ}, 3^{\circ}$ e 104 do CDC.

Entretanto, em razão de alterações pontuais e casuísticas na legislação, do veto presidencial ao artigo 333 da Lei 13.105/2015 (Novo Código de Processo Civil), que previa a possibilidade de conversão das ações individuais em coletivas, bem como em razão do recente arquivamento do Projeto de Lei $\mathrm{n}^{\mathrm{o}}$ 282/2012 no âmbito do Senado Federal, relativo ao aprimoramento da tutela processual coletiva do consumidor, indaga-se se já não se está diante de um período de involução da proteção coletiva do consumidor, tal como ocorreu nos Estados Unidos em sua história recente.

O objetivo desta análise ao se olhar para o Direito Estadunidense e para as experiências judiciais daquele país no âmbito da proteção processual coletiva do consumidor é conceber uma projeção de futuro para a própria realidade brasileira, na medida em que o capítulo processual da Lei 8.078/90 (Código de Defesa do Consumidor) foi elaborado a partir do modelo norteamericano, em especial seguindo a mesma sistemática das class actions, guardadas algumas diferenças, em especial no que se refere à legitimação ativa e passiva.

A partir da delimitação do problema de pesquisa e do objetivo central e por intermédio de estudo teórico e bibliográfico, o artigo propõe-se a identificar as razões que levaram às alterações legislativas e à consequente maior restrição no manuseio das ações coletivas nos Estados Unidos, com especial atenção ao surgimento da ação coletiva passiva (Defendant Class Action) e de que modo seria possível antecipar cenários e evitar a reprodução desse ideário conservador no Brasil, blindando a posição jurídica do consumidor, sobretudo quando identificado no plano transindividual como categoria econômica e juridicamente fragilizada. 


\section{AS DIFERENÇAS ENTRE A LEGITIMAÇÃO COLETIVA BRASILEIRA E A ESTADUNIDENSE}

O microssistema normativo brasileiro, ao mesmo tempo em que ampliou os espaços políticos de atuação judicial da sociedade civil concebida a partir de uma perspectiva solidária de grupo e plural, já tinha criado as bases materiais para a ocupação desses espaços, pelo menos no plano teórico.

A legitimação das class actions norte-americanas, por sua vez, distancia-se da concepção da lei brasileira, na medida em que o legitimado não é pré-definido, mas sua identificação decorre de uma análise efetiva do juiz (dotado de poderes amplos) acerca da representação adequada daquele que se apresenta como legitimado, que deve ser, necessariamente, um dos membros que compõe o grupo. A verificação dessa "adequação" será realizada pela análise de vários requisitos rigorosos e que, uma vez certificada a ação como "coletiva", a coisa julgada que dela decorre atingirá a todos, indistintamente e independentemente do resultado, ressalvadas as hipóteses de sua relativização previstas no artigo 103 do CDC (NEGRÃO, 2004, p. 300-301).

No capítulo processual do CDC, observa-se no artigo 82 uma reprodução quase que literal do artigo $5^{\circ}$ da LACP, na medida em que se constata os mesmos legitimados para a propositura das ações coletivas, a saber: Ministério Público, União, Estados, Municípios, Associações Representativas de Defesa do Consumidor e a Defensoria Pública, esta com referência exclusiva na LACP, todos identificados como os únicos autorizados a instrumentalizar a proteção coletiva do consumidor em juízo.

De fato, o que norteou a opção legislativa foi o critério de representação adequada, claramente inspirada em instrumentos do direito comparado, mormente a class action norteamericana (NEGRÃO, 2004, p. 300-301). Entretanto, no Brasil, a ideia de representação adequada foi presumida e conferida pelo legislador a um rol taxativo de legitimados ativos, sendo vedada qualquer interpretação judicial extensiva nesse sentido.

Prossegue Negrão (2004, p. 300-301):

A noção de adequação da representação distanciou-se do modelo inspirador (o norte-americano) na medida em que houve expressa determinação legal prévia, ensejando, assim, o reconhecimento "a priori" (exceto nos casos em que a lei exige a coincidência da finalidade institucional e a existência por mais um ano) dos adequados legitimados. Assim, reconhecemos que a questão da adequação, no caso da ação coletiva brasileira, vincula-se a um aspecto objetivo, qual seja, da pretensão legal de erigir aqueles que teriam melhores condições de proteger o interesse e não os sujeitos eventualmente vinculados 
com o direito coletivo. Por essa razão que a coisa julgada da ação coletiva brasileira dá-se apenas para favorecer o indivíduo e nunca prejudicá-lo (exceto no caso deste intervir como assistente litisconsorcial).

Optou a lei, assim, por eleger determinados entes, que por sua posição social, política e jurídica, têm condições de serem apontados como os únicos titulares daquele jeito de ação coletiva, para que a prestação jurisdicional seja eficaz.

Como se observou supra, no Brasil, para a averiguação da legitimação coletiva, é suficiente o exame do tex to da lei. Não poderia o magistrado, por exemplo, afirmar que um ente legalmente legitimado não tem, em determinado caso, o direito de conduzir o processo. Neste caso, o legislador teria estabelecido um rol legal taxativo de legitimados, firmando uma presunção absoluta de que seriam "representantes adequados", não cabendo ao magistrado fazer essa avaliação caso a caso (DIDIER; ZANETI, 2009, p. 204-205).

Para Didier e Zaneti (2009, p. 204-205): “A verificação da adequacy of representation seria tarefa do legislador. A legitimação coletiva seria, pois, ope legis.”.

Todavia, há o argumento contrário de que a análise da legitimidade deveria ser critério semelhante definido pela legislação federal norte-americana, onde se exerce um verdadeiro controle judicial daquilo que seria a "representatividade adequada". Em outras palavras, permite-se que o magistrado possa examinar e controlar a legitimação coletiva no caso concreto, conforme as características do legitimado (DIDIER; ZANETI, 2009, p. 204-205).

No Direito Estadunidense, há a exigência de que o legitimado seja um membro do grupo e apresente características próprias que lhe determinem como adequado representante do grupo, como uma espécie de seleção prévia para a eventual certificação da ação. Para esses autores, a legitimação no Brasil, mesmo dos entes públicos, deveria passar por um filtro judicial, pois não bastaria a previsão legal da legitimação. Parte-se da premissa de que não é razoável imaginar que uma entidade, pela simples circunstância de estar autorizada em tese para a condução de processo coletivo, possa propor qualquer demanda coletiva, pouco importando suas peculiaridades (DIDIER; ZANETI, 2009, p. 205).

Didier e Zaneti (2009, p. 205, grifo do autor) complementam o raciocínio:

É preciso verificar, a bem de garantir a adequada tutela destes importantes direitos, se o legitimado coletivo reúne os atributos que o tornem representante adequado para a melhor condução de determinado processo coletivo, devendo essa adequação ser examinada pelo magistrado de acordo com critérios gerais, preferivelmente previamente estabelecidos ou indicados em juízo. Todos os critérios para aferição da representatividade adequada devem ser examinados a partir do conteúdo da demanda coletiva.

A análise de legitimação coletiva e, nessa linha de raciocínio, da própria representação adequada ocorreria em duas etapas: 
Primeiramente, verifica-se se há autorização legal para que determinando ente possa substituir os titulares coletivos. A seguir, o juiz faz o controle in concreto da adequação da legitimidade para aferir, sempre motivadamente, se estão presentes os elementos que asseguram a representatividade adequada dos direitos em tela. (DIDIER; ZANETI, 2009, p. 206, grifo do autor).

No sistema brasileiro, a diversidade de atores, além de multiplicar exponencialmente as vias de discussão política no Judiciário, gera uma salutar competição entre os legitimados, obrigando-os a exercer uma fiscalização informal recíproca, através de debates constantes e pela própria exigência de prestação de contas junto à sociedade civil, aqui ocupante de poder decisório dos mais relevantes, como se falará mais à frente.

No Brasil, conquanto se reconheça um rol relativamente amplo de legitimados, identifica-se o grave e crescente problema de acompanhamento das ações coletivas, independente de quem seja a entidade autora (associações de consumidores, Ministério Público, ou qualquer outro legitimado coletivo), pois se nota uma preocupação maior com as tutelas de urgência, do que com o julgamento do mérito em si, nem sequer com o cumprimento de eventuais decisões favoráveis.

Após o ajuizamento da ação, pouco tem sido feito para se conseguir a manutenção das tutelas provisórias, sobretudo no âmbito recursal, sendo as ações abandonadas ao mero impulso oficial, o que, como é fato público e notório no âmbito das varas privativas de feitos da fazenda pública (por onde tramitam os referidos processos), funciona apenas nos livros de teoria geral do processo no Brasil, pois estão todas abarrotadas, com estrutura operacional deficiente e reduzidíssimo quadro de pessoal.

Como resultado desse cenário, muito dificilmente uma ação civil pública ou ação coletiva tem um desfecho meritório e é ainda mais raro identificar o cumprimento de uma sentença condenatória, o que acaba por favorecer o fornecedor que, agindo na infra legalidade, se locupleta indevidamente às custas do consumidor por práticas abusivas e outros comportamentos ilícitos.

A questão é agravada pela demora e falta de efetividade na ação coletiva, aqui entendida como uma das últimas esperanças na correção dos comportamentos ilícitos do fornecedor pelo Judiciário, fortalecendo ainda mais o status de superioridade jurídica e econômica daquele em relação ao consumidor vulnerável e, muitas vezes, hipossuficiente.

Nessa linha de raciocínio, seria importante dotar os legitimados oficiais, aqui entendidos os que têm um braço do poder público, como o Ministério Público, a Defensoria Pública, entidades federativas de mecanismos mais eficazes de acompanhamento processual, 
para que não se acomodem com as prerrogativas da fazenda pública de que gozam em juízo e, por isso, passem a negligenciar os interesses que estão substituindo nas demandas coletivas.

Precisam atuar como se fossem verdadeiros advogados da coletividade de consumidores, com interesse real e permanente na obtenção de um resultado rápido e satisfatório da lide e não apenas aumentar a estatística de ações ajuizadas ou usufruir da fama midiática que a propositura de algumas ações coletivas pode oferecer.

Essa exigência despertou para o surgimento de uma jurisdição civil coletiva que foi um reflexo da necessidade premente erigida no bojo da sociedade marcada por relações de massa. Essa sociedade clama pela solução equânime de conflitos dispersos, sendo certo que sua estrutura inaugurou uma nova conceituação da relação jurídica processual e do próprio direito de ação (NEGRÃO, 2004, p. 297-298).

Negrão (2004, p. 299) sustenta que:

A ação coletiva possui papel importante na busca da efetividade da jurisdição, na medida em que, de um lado, representa um meio de se fazer valer uma amplitude nos limites da coisa julgada (e, portanto, possível ampliação subjetiva dos efeitos concretos dessa mesma coisa julgada) significando, com isto, maior acesso à justiça e, de outro lado, contribui para a economia processual (apenas uma decisão, várias relações tuteladas).

Outra mudança relevante viria do próprio Judiciário, seja voluntariamente através da imposição de metas de julgamento das ações coletivas ou pela descentralização no julgamento das ações pelas varas privativas, o que pulverizaria a competência regimental para todas as demais varas cíveis, garantindo uma maior fluidez nos julgamentos, o que poderia ser determinado pela iniciativa dos órgãos diretivos dos Tribunais de Justiça e Tribunais Regionais Federais ou por imposição do Conselho Nacional de Justiça (CNJ), órgão de controle externo do Judiciário, criado pelo avento da Emenda Constitucional n ${ }^{\circ} 45$ de 08 de dezembro de 2004, que vem fiscalizando e modernizando a atividade judiciária no Brasil nos últimos anos. ${ }^{2}$

Em meio a essas questões, exsurge a vulnerabilidade do consumidor nas relações de consumo, como uma das principais preocupações da sociedade pós-moderna, que se vê inserida num processo mundial de globalização, avanços tecnológicos, difusão do crédito irresponsável, massificação dos contratos, propagação de práticas comerciais abusivas, desafiando a intervenção dos órgãos integrantes da Política Nacional das Relações de Consumo, obrigando a todos os legitimados coletivos a ocuparem o seu papel, incluindo-se aí as entidades

\footnotetext{
${ }^{2}$ Neste particular, cite-se a meta $\mathrm{n}^{\circ} 18$ do $\mathrm{CNJ}$, relativa ao julgamento das ações de improbidade administrativa e crimes contra a administração pública.
} 
federativas, através de seus órgãos procuratórios, que, por questões políticas e administrativas, ainda não assumiram tal relevante compromisso social em prol de um modelo de consumo sustentável pela via processual coletiva.

Isso porque já há uma participação do Estado, mesmo que de maneira insuficiente, através do PROCON (Grupo Executivo de Proteção ao Consumidor), órgão que pode ser municipal ou estadual, integrando a administração direta ou indireta, que exerce poder de polícia fiscalizatório e, ao mesmo tempo, presta atendimento individual ao consumidor, mas que tem se mostrado inoperante quanto à propositura das ações coletivas. Prerrogativa essa consagrada nos artigos $5^{\circ}$, caput da Lei. 7.347/85 (LACP) e 82, II do CDC, in literis:

Art. $5^{\circ}$ - A ação principal e a cautelar poderão ser propostas pelo Ministério Público, pela União, pelos Estados e Municípios. [...] (Lei 7.347/85)

Art. 82- Para fins do art. 81, parágrafo único, são legitimados concorrentemente:

II- a União, os Estados, os Municípios e o Distrito Federal (CDC).

Não se admite que o microssistema de proteção ao consumidor, que cria um mecanismo excepcional de defesa coletiva, tornando eficaz, célere e efetiva a tutela processual do consumidor, possa ser desprestigiado por alguns dos legitimados extraordinários.

Deve-se esclarecer, todavia, que o Ministério Público não possui uma legitimidade preferencial para agir na defesa dos interesses metaindividuais do consumidor, como equivocadamente se convencionou acreditar na sociedade, mas todas as entidades mencionadas nos dispositivos supra, inclusive as entidades federativas, em nome próprio, ou através do PROCON, poderão ajuizar a competente ação coletiva para a defesa dos interesses coletivos do consumidor.

Todos os avanços e inovações jurídicas trazidas à discussão com a consolidação do Microssistema de proteção ao consumidor (CDC, LACP, Portarias da Secretaria de Direito Econômico do Ministério da Justiça), que tornam mais efetiva a tutela e aumentam sobremaneira as possibilidades de êxito nas demandas, poderão ser manejadas pelas entidades federativas, sem qualquer ônus adicional em suas finanças, bastando, todavia, alargar as competências institucionais dos respectivos órgãos procuratórios.

Tem-se, na verdade, através da Ação Civil Pública, um instrumento importantíssimo para que se alcance a tão almejada harmonia das relações de consumo, estabelecendo um novo 
padrão de comportamento para as empresas que atuam no mercado, disponibilizando produtos e serviços, que nem sempre estão de acordo com as reais expectativas do consumidor e, tampouco, com os rigorosos índices de qualidade, quantidade e preço, consubstanciados na Política Nacional de Defesa do Consumidor.

\section{A INVOLUÇÃO LEGISLATIVA DA TUTELA COLETIVA NOS ESTADOS UNIDOS E O MENOR ALCANCE DA RULE 23}

Segundo Arthur Miller (apud GIDI, 2007, p. 60-61), o aumento do número de ações coletivas propostas nos Estados Unidos deveu-se não à reforma da letra da lei processual, mas às alterações pelas quais passava a sociedade americana, em transição para um modelo massificado, e às consequentes alterações no direito material. Segundo o autor, a tendência teria sido substancialmente a mesma, seja com a redação original da Rule 23 , seja sob a égide da Rule 38 das Federal Equity Rules de 1912, ou mesmo se vigorassem ainda as práticas históricas do Bill of Peace inglês.

Em 1995, o Congresso americano, dominado pelo Partido Republicano, promulgou o Private Securities Act-Pub.L.No.104-67, 109 Stat.737 (1995). Ao contrário da Rule 23, que foi promulgada e emendada pela Suprema Corte, essa lei (statute) é uma norma emanada do Poder Legislativo, tendo sido codificada no Título 15 do United States Code (e reproduzida no apêndice).

Para Gidi (2007, p. 62), o surgimento da lei teria uma justificativa autoritária:

Subdividida em títulos aterrorizantes como "Redução de litígios abusivos" e "Redução de acordos coercivos", essa lei foi uma resposta histérica ao poderoso lobby de empresas de tecnologia de ponta, que se sentiam sufocadas com o constante monitoramento de suas atividades realizado pelos advogados especializados em ações coletivas.

O autoritarismo da lei ficou evidenciado em inúmeras normas processuais específicas para as ações coletivas do mercado de valores (securities class actions), cujo objetivo declarado era o de evitar práticas abusivas (reais e imaginárias) quanto ao manuseio da via coletiva e o consequente prejuízo à livre iniciativa.

Todavia, na prática, o real objetivo da lei era:

[...] limitar consideravelmente o acesso à justiça das pretensões coletivas nessa área do direito. A lei atinge tal objetivo através das mais variadas formas, fechando o cerco contra os investidores, tanto criando artificialmente embaraços processuais à propositura e à manutenção de ações, à autuação dos advogados, e à descoberta de fraudes, como alterando o direito material em 
benefício das empresas, impondo limites ao valor dos honorários advocatícios e até mesmo das indenizações. (GIDI, 2007, p. 62).

Não por coincidência, o Partido Republicano é aquele ideologicamente identificado com o capital e com as grandes empresas. O presidente na época, o democrata Bill Clinton, sob a influência do poderoso lobby dos advogados especializados em representar judicialmente os grupos em ações coletivas (plaintiff bar), vetou o projeto de lei (Bill), mas o Congresso, de maioria republicana, rejeitou o seu veto e aprovou a lei, que ficaria adstrita às securities class actions (GIDI, 2007, p. 62).

Outra investida contra as ações coletivas americanas foi desferida em 2005, quando o Congresso, ainda dominado pelo partido Republicano, promulgou outra lei (statute), o Class Action Fairness Act (CAFA) (Pub. L. No. 109-2,119 Stat.4). O CAFA foi codificado no Título 28 do United States Code e, ao contrário do Private Securities Litigation Act de 1995, é aplicável genericamente a todas as ações coletivas. Trata-se de um texto extremamente longo, confuso e atécnico (GIDI, 2007, p. 62).

Em linhas gerais, sob a justificativa de evitar que o assédio e a influência regional pudessem interferir no julgamento das ações de maior relevância contra as grandes corporações, transferiu-se para a Justiça Federal a competência para julgar as ações coletivas de alto valor (cinco milhões de dólares), envolvendo pretensões de membros situados em mais de um Estado (interstate class actions).

Buscou-se federalizar o julgamento das ações coletivas de interesse nacional, retirando das mãos de juízes eleitos em Estados rurais, para transferi-las para Juízes Federais nomeados pelo Presidente e confirmados pelo Senado, na tentativa de dificultar decisões tendentes a favorecer as massas, muito comuns no âmbito estadual, o que gerava um efeito multiplicador e claramente desproporcional de novas ações de classe naquelas localidades.

Esses tribunais eram conhecidos de maneira pejorativa como magnet state courts. Um exemplo teratológico é o de um juiz numa cidadezinha no Alabama, que certificou mais ações coletivas de interesse nacional (nationwide class actions), do que todos os 900 juízes juntos. Alabama e Lousiana eram considerados “o paraíso das class actions” (GIDI, 2007, p. 63).

Todavia, a despeito do maior nível de restrição legislativa no processamento das ações coletivas, a sociedade americana vem sendo exposta a práticas abusivas cada vez mais complexas e sofisticadas. Os instrumentos de massificação comercial estão construindo uma sociedade assustadoramente homogênea, em que o próprio senso estético e de cultura está sendo 
massificado, obrigando a todos a consumirem os mesmos produtos e serviços, moldando gostos através de uma publicidade agressiva e manipuladora.

Nesse contexto, os riscos de dano coletivo são cada vez mais frequentes e suas consequências, devastadoras, daí porque a limitação de acesso à justiça por meio das ações coletivas vai de encontro à própria exigência de participação cívica da solidariedade.

É importante destacar que a Rule 23 vem sendo estudada incessantemente desde o início da década de 90 por inúmeras comissões governamentais, com o objetivo de fundamentar com base no acompanhamento diário dos conflitos de consumo uma reforma mais aprofundada, que aprimore o processo coletivo, como também a estrutura das class actions. Nem todas as mudanças visam favorecer o manuseio do instituto, mas são bastantes relevantes os estudos nas seguintes questões: a) maior controle das práticas abusivas, ampliando o controle pré e pós contratual, b) regulamentação das settlement das class actions e a adequação do instrumento às peculiaridades da tutela coletiva de ilícitos civis cometidos em larga escala (mass torts), principalmente aqueles decorrentes de eventos dispersos em termos de tempo, espaço e intensidade, como é o caso da exposição a produtos químicos nocivos (mass toxic torts). (GIDI, 2007, p. 64).

O principal desafio na defesa de um consumo responsável no direito norte-americano reside na tentativa de se alcançar um ponto de equilíbrio entre os aspectos positivos e bem sucedidos das class actions, mas que se consiga extirpar os problemas encontrados na sua prática, sobretudo quando da utilização abusiva em prol de interesses financeiros escusos em demandas aventureiras, vencer obstáculos impostos pelas indiossincrasias da cultura, do processo civil, do sistema federativo de distribuição do poder, da organização judicial e da estrutura da advocacia nos Estados Unidos, que propicia o ambiente para a prática de condutas antiéticas por parte dos advogados de ambas as partes (GIDI, 2007, p. 65).

As ações coletivas, são uma das três expressões da solidariedade emancipatória no direito consumerista brasileiro ${ }^{3}$, que garante não apenas a tutela material de direitos básicos do consumidor, mas também o coloca numa posição de igualdade processual, para impingir ao fornecedor e ao Estado o cumprimento de metas e obrigações mais claras, definidas a partir da participação de todos no debate racional permanente inaugurado pelas políticas nacional e estaduais das relações de consumo.

\footnotetext{
${ }^{3}$ As outras duas expressões estão na Política Nacional das Relações de Consumidor (artigos $4^{\circ}$ e $5^{\circ}$, CDC) e na Convenção Coletiva de Consumo (artigo 107, CDC).
} 
Da mesma forma como se sucedeu com o reconhecimento das virtudes jurídicas e políticas das demandas coletivas no Brasil, introduzidas a partir do microssistema normativo de defesa do consumidor, parece que o legislador americano não tinha uma ideia precisa do que estava fazendo quando reformulou a Rule 23 na década de 60, democratizando a tutela processual coletiva.

À medida que a ação foi sendo utilizada na prática e a sua força foi sendo revelada, começou-se uma campanha em sentido contrário, justamente para restringir sua atuação, o que não deixa de ser um grande retrocesso no processo de aprimoramento das relações de consumo. É evidente que tanto em decisões da Suprema Corte, quanto em alguns atos do Congresso Americano se observa, de forma gradual, a restrição de seus efeitos na Justiça Federal (GIDI, 2007, p. 65).

Não há dúvida de que o principal interesse oculto na transformação da Rule 23 foi criar mecanismos que restringissem seu manejo e utilidade prática nas questões de interesse coletivo, muito embora a situação política nos Estados Unidos esteja em completo impasse, dividida quase igualmente entre aqueles que criticam os abusos praticados pelos autores das ações coletivas (republicanos) e aqueles que criticam os abusos praticados pelos detentores do poder econômico (democratas). Essa polarização acaba por impedir uma proposta mais ambiciosa ou polêmica.

Não é politicamente viável uma reforma que elimine completamente as ações coletivas do ordenamento jurídico americano, nem uma reforma que elimine os obstáculos existentes e potencialize a sua eficácia. Em todo caso, com o conhecimento que se tem hoje da potência das ações coletivas, se a Rule 23 não existisse, uma proposta que a instituísse não seria aprovada hoje nos Estados Unidos (GIDI, 2007, p. 65-66).

\section{A AÇÃO COLETIVA PASSIVA (DEFENDANT CLASS ACTION)}

Muitos trabalhos acadêmicos se debruçam sobre as virtudes da legitimação extraordinária prevista para as ações coletivas, porém o mesmo esforço argumentativo e entusiasmo doutrinário não são verificados quando se enfrenta a tormentosa questão da legitimidade passiva da própria classe, porquanto não existente no direito brasileiro a figura da defendant class action do direito norte americano, prevista na alínea (a) (3), da Rule 23, das Federal Rules of Civil Procedure. 
No direito norte-americano, quando se definem os pré-requisitos para a ação de classe, observa-se que um ou mais membros de uma classe podem processar ou ser processados como partes, representando a todos, apenas se, dentre outras hipóteses, as demandas ou exceções das partes representativas são típicas das demandas ou exceções da classe.

Haverá ação coletiva passiva quando um argumento humano for colocado como sujeito passivo de uma relação jurídica afirmada na petição inicial. Formula-se demanda contra uma dada coletividade. Os direitos afirmados pelo autor da demanda coletiva passiva podem ser individuais ou coletivos (lato sensu) - nessa última hipótese, há uma ação duplamente coletiva, pois o conflito de interesses envolve duas comunidades distintas (DIDIER; ZANETI, 2009, p.399).

De acordo com o regime jurídico de toda ação coletiva, exige-se para a admissibilidade da ação coletiva passiva que a demanda seja proposta contra um "representante adequado" (legitimado extraordinário para a defesa de uma situação jurídica coletiva) e que a causa se revista de "interesse social" (DIDIER; ZANETI, 2009, p. 399).

É justamente o alcance dessa representação passiva que preocupa o legislador nacional, porquanto o sistema processual consumerista foi muito bem ajustado para lidar com a legitimação extraordinária ativa, sob a forma de substituição processual, justamente com o intuito de fomentar a propositura das ações coletivas, sem com isso restringir ou impedir a tutela dos interesses individuais subjetivos direta, ou indiretamente relacionados com os interesses transindividuais instrumentalizados sob a forma de demanda coletiva.

As próprias regras atinentes aos efeitos e execução da coisa julgada e à litispendência, previstas, respectivamente, nos artigos 95, 97, §§ $1^{\circ} \mathrm{e} 2^{\circ}$ dos artigos 103 e 104 do CDC, já preservam a tutela individual, independente do resultado das ações coletivas, como uma espécie de blindagem processual aos interesses dos substituídos em relação a alguma conduta comissiva ou omissiva dos substitutos, prejudicial ao grupo ou categoria de consumidores.

Todavia, no que se refere à definição da legitimação passiva para a Defendant Class Action, embora não haja vedação expressa nem do CDC, tampouco na LACP, pois tanto no artigo 82 , como no $5^{\circ}$, respectivamente, se fala apenas de legitimação concorrente, pelo que se presumiria a possibilidade dos mesmos legitimados que atuam no polo ativo da tutela coletiva também figurarem no polo passivo.

A premissa acima, entretanto, não pode ser tida como verdadeira, porquanto não se pode conceber, por exemplo, uma associação representativa de defesa do consumidor, com pouca ou nenhuma experiência processual e sem lastro financeiro para suportar o 
acompanhamento de demanda coletiva, a despeito da isenção de custas e honorários prevista no artigo 18 da LACP, sendo escolhida pelo fornecedor para defender a negação de direito coletivo alusivo a toda coletividade, vindo a prejudicá-la, se julgados procedentes os pedidos, ou mesmo pelo simples risco processual de perda de prazos e maiores efeitos da preclusão para quem litiga no polo passivo.

Essa possibilidade, sem nenhuma espécie de proteção específica na legislação processual brasileira, seria contraditória em relação a toda lógica de incremento à defesa coletiva do consumidor, como uma das expressões da solidariedade emancipatória.

Daí porque deve prevalecer uma interpretação restritiva quanto aos dispositivos atinentes à legitimação para agir previstos no CDC (art. 82) e LACP (art. $5^{\circ}$ ), na medida em que se o legislador brasileiro não previu expressamente a possibilidade dos legitimados coletivos atuarem no polo passivo de uma demanda, com toda a cautela necessária para preservar os interesses individuais dos consumidores, não se poderia conceber tal atuação que poderia vir a ser desastrosa para o grupo ou categoria, como por exemplo, na formação de uma coisa julgada coletiva que inibisse a propositura de ações individuais, ou que impusesse ao consumidor a redução forçada de padrões de qualidade e segurança de produtos e serviços.

Nessa linha de raciocínio, Hugo Nigro Mazzilli (1997, p. 215) declara a existência de limitação na legitimação extraordinária, na medida em que os legitimados coletivos ostentariam essa condição apenas no âmbito ativo, não podendo representar passivamente a categoria, classe ou grupo, nem mesmo em reconvenção. Da mesma forma, o Ministério Público, por ser desprovido de personalidade jurídica, não poderá ser parte passiva da relação processual.

Gidi (2007, p. 51-52), da mesma maneira, pondera que “[...] somente se confere legitimidade ad causam aos entes elencados no art. $5^{\circ}$ da LACP e no art.82 do CDC que não podem figurar como réus nas ações coletivas".

Para que fosse possível levar a cabo o reconhecimento da legitimidade passiva para os mesmos legitimados ativos nas ações coletivas, além dos mecanismos de blindagem processual específica para os direitos individuais subjetivos referidos alhures, seria fundamental também fortalecer a posição do órgão jurisdicional na verificação da adequacy of representation, para que fosse possível, na sentença, vincular todos os componentes da classe, independentemente de sua posição individual no processo.

Nesse sentido, Lenza (2003, p. 199, grifo do autor) adverte:

Valendo-se da experiência norte-americana, falar-se em ações coletivas a serem promovidas em face da classe implicaria revitalizar o papel do juiz como verdadeiro protagonista, que deverá assumir a imprescindível missão 
de identificação de classe (defining function) e de controle sobre a efetiva capacidade de sua representação (adequacy of representation).

Outrossim, não se pode olvidar que a legitimação passiva dos atores coletivos contrariaria os limites subjetivos da coisa julgada, nos termos do artigo 506 do CPC/2015, quando se estenderia aos substituídos a pecha de terceiros estranhos à relação processual e que, portanto, não poderiam ser prejudicados.

Ademais, no que tange às garantias constitucionais da ampla defesa e contraditório, Pedro da Silva Dinamarco (2005, p. 268-273) assevera:

No plano constitucional, a admissibilidade da presença de uma associação no pólo passivo, como substituto de terceiros, violaria a garantia individual do contraditório e da ampla defesa (art. $5^{\circ}$, inc. LV), bem como a do devido processo legal (art. $5^{\circ}$, inc. LIV). Assim, é inimaginável que os efeitos de uma sentença, em qualquer processo, possam prejudicar o indivíduo sem que lhe seja dada a ampla oportunidade de se defender e de lançar mão dos recursos inerentes àqueles princípios constitucionais.

A ação coletiva passiva não pode ser vista, em qualquer caso, como algo nocivo à tutela processual do consumidor, porquanto haverá situações em que o fornecedor terá o legítimo interesse processual de se preservar de demandas individuais de cunho aventureiro, correndo o risco de significativa perda financeira pelo simples ônus de se defender em todas elas, sobretudo em hipóteses de clara litigância de má fé.

Há autores, contudo, que defendem a propositura de ação civil pública em face de associação, na condição de substituta processual, mas desde que especificamente indicada, no polo passivo, como litisconsorte dos associados que serão atingidos pela coisa julgada, sendo vedada a legitimidade extraordinária passiva exclusiva da associação (ALMEIDA, 2003, p. 354-355).

Prossegue Almeida (2003, p. 355), ao afirmar que caso seja possível e viável processual e economicamente, deverão ser pessoalmente citadas as pessoas diretamente interessadas e que serão atingidas pelos limites subjetivos da coisa julgada coletiva.

Todavia, essa não parece ser a melhor alternativa, porquanto seria necessária a citação das pessoas diretamente interessadas no objeto da ação, para que se habilitassem no polo passivo como litisconsortes passivos necessários, nos termos do artigo 94 do CDC, para que corressem o mesmo risco processual do substituto processual.

A habilitação do consumidor individual antes do trânsito em julgado de uma ação coletiva já não é vantajosa, quando o edital se referir ao polo ativo da ação, quiçá na hipótese de integração do polo passivo, havendo ainda o risco adicional de ser deferida a citação por 
edital dos interessados ante a eventual inviabilidade da citação pessoal, colocando-os numa posição de fragilidade processual extrema, o que não parece lógico defender.

Muito pertinente é a vinculação exemplificativa de Lenza (2003, p. 202-203) entre a possibilidade de se admitir a defendant class action no direito brasileiro com o instituto da convenção coletiva de consumo.

Como já referido no presente trabalho, a convenção coletiva, ao lado da política nacional das relações de consumo e da legitimidade extraordinária das associações representativas de defesa do consumo representam as três expressões mais latentes da ideia de solidariedade e pluralismo jurídico no direito do consumidor.

Pelo artigo 107 do CDC, poderá ser instaurado um diálogo racional permanente entre as entidades civis de consumidores e as associações de fornecedores ou sindicatos de categoria econômica, cujo resultado importará na assunção de compromissos normativos recíprocos entre as partes, com o objetivo maior de aperfeiçoamento das relações de consumo, seja quanto à qualidade e segurança de produtos e serviços, seja quanto à imposição de metas de atendimento, seja no que tange à padronização de comportamentos tidos por leais entre as partes, rumo a um estágio de amadurecimento ético e cívico.

Como efeito natural do registro da convenção no cartório de títulos e documentos está sua plena eficácia perante as partes signatárias, e respectivos filiados e associados, razão pela qual um eventual descumprimento de qualquer das disposições do aludido contrato, após sua celebração, autorizaria a propositura da ação coletiva passiva em face de entidade inadimplente. (LENZA, 2003, p. 202-203).

Lenza (2003, p. 203), em conclusão, pondera em sentido favorável à ação coletiva passiva, desde que verificada a adequação do representante passivo da classe por parte do juiz, ao afirmar que:

Assim, pode-se afirmar ser perfeitamente possível a propositura de ação em face de classe, a fim de se realizar todas as situações práticas decorrentes dos exemplos já imaginados pela doutrina. Reconhece-se que esse tipo de ação não é comum. Não se pode, contudo, ignorá-la. Imprescindível, outrossim, a revisitação do papel do juiz na aferição da idoneidade do representante da classe.

Para esta hipótese de representação adequada, como requisito para a viabilidade de ação coletiva passiva, fica evidente o exemplo que se segue: uma operadora de telefonia móvel propõe ação declaratória em face da Agência Nacional de Telecomunicações (ANATEL), 
objetivando a declaração de licitude de condição geral de contratação, ou mesmo de cláusula de contrato padrão.

Proposta a ação, verificada a representatividade adequada pelo juízo, o que será melhor aferido a partir da intimação do Ministério Público para atuar como fiscal da lei, nos termos do $\S 1^{\circ}$ do artigo $5^{\circ}$ da LACP, e, mais recentemente, com a entrada em vigor do Novo CPC, como defensor da ordem jurídica, conforme prevê o art. 176, do CPC/2015, a ação poderá prosseguir normalmente, havendo, inclusive, a possibilidade da entidade ré apresentar reconvenção, pretendendo, por exemplo, a declaração de nulidade da condição geral ou cláusula contratual e, ainda, pedido condenatório por dano moral coletivo.

O que toma a ação coletiva passiva digna de um tratamento diferenciado é a circunstância de a situação jurídica titularizada pela coletividade encontrar-se no polo passivo do processo. A demanda é dirigida contra uma coletividade, sujeita de uma situação jurídica passiva (um dever ou um estado de sujeição, por exemplo). Da mesma forma que a coletividade pode ser titular de um dever ou um estado de sujeição (situações jurídicas passivas). É preciso desenvolver dogmaticamente a categoria das situações jurídicas coletivas passivas: deveres e estado de sujeição coletivos. As propostas de Código Modelo ${ }^{4}$ para processos coletivos, embora tenha previsto as ações coletivas passivas, apenas cuidaram dos "direitos coletivos" (DIDIER; ZANETI, 2009, p. 400).

Para Didier e Zaneti (2009, p. 400):

Não há definição das situações jurídicas passivas coletivas, cujo conceito deverá ser extraído dos artigos que conceituam os "direitos", aplicados em sentido inverso: deveres e estados de sujeição indivisíveis e deveres e estado de sujeição individuais homogêneos (indivisíveis para fins de tutela, mas individualizáveis em sede execução ou comprimento). Como sugestão para o aprimoramento dos projetos, é recomendável que se acrescente um artigo com essas definições no capítulo sobre ação coletiva passiva.

Concluem, portanto, que:

Haverá uma ação coletiva passiva, portanto, em toda demanda onde estiver em jogo uma situação coletiva passiva. Seja como correlata a um direito individual, seja como correlata a um direito coletivo. (DIDIER; ZANETI, 2009, p. 400).

\footnotetext{
${ }^{4}$ No âmbito dos países íbero-americanos, surge, no ano de 2004, um novo e verdadeiro marco para o Direito Processual Coletivo, que é o Código de Modelo de Processos Coletivos Íbero-Americanos de Direito Processual. Constituído com base na legislação brasileira, mas com várias modificações e inovações, e com a participação de quatro professores brasileiros, o novel Código-Tipo passou a ser uma importante fonte de inspiração para os países latino-americanos, servindo, também, como parâmetro para se repensar e aperfeiçoar o sistema brasileiro. (DIDIER; MOUTA, 2009, p. 91).
} 
Por fim, mesmo diante da omissão legislativa quanto ao reconhecimento expresso da ação coletiva passiva (defendant class action) no direito brasileiro, não se ignora sua existência implícita, conforme identificado acima, o que funcionará como importante trunfo para o fornecedor, sobretudo em situações de risco processual e econômico, diante de uma pluralidade de demandas individuais infundadas acerca de determinado aspecto da relação de consumo.

Ademais, mesmo que não se reconheça a adequação da representação passiva em demanda coletiva movida pelo fornecedor, subsiste em seu favor a garantia de que os efeitos da coisa julgada coletiva (erga omnes ou ultra partes) repercutam em desfavor de todo o grupo, coletividade e, no litisconsórcio unitário referido nos artigos 94 e $§ 2^{\circ}, 103$ do CDC, também na esfera individual subjetiva dos consumidores, em havendo a improcedência parcial ou total dos pedidos, o que, naturalmente, já preservaria os interesses econômicos e processuais do fornecedor diante de novas ações acerca do mesmo objeto, já atingido pelo manto protetor da coisa julgada.

$\mathrm{Na}$ tentativa de dissipar a controvérsia, os Anteprojetos de Código de Processo Coletivo introduziram ao debate uma significativa novidade ao disporem expressamente sobre a ação coletiva passiva. Previram, assim, que qualquer espécie de ação pode ser proposta contra uma coletividade organizada ou que tenha representante adequado (DIDIER; MOUTA, 2009, p. 118). ${ }^{5}$

\footnotetext{
${ }^{5}$ O Anteprojeto de Código Brasileiro de Processos Coletivos, elaborado pelo Instituto Brasileiro de Processos Coletivos, está estruturado em cinquenta e dois artigos, reunidos em seis capítulos: I - Das demandas coletivas; II - Da ação coletiva ativa (com duas seções: I - Disposições gerais; II - Da ação coletiva para a defesa de interesses ou direitos individuais homogêneos); III - Da ação coletiva passiva originária; IV - Do mandado de segurança coletivo; V - Das ações populares (com duas seções: I - Da ação popular constitucional; II - Ação de improbidade administrativa); VI - Disposições finais.

O Anteprojeto de Código Brasileiro de Processos Coletivos, proveniente dos Programas de Pós-Graduação da UERJ e da UNESA, por sua vez, procurou organizar um pouco mais as normas propostas, subdividindo os seus 60 artigos em cinco partes: I - Das ações coletivas em geral; II - Das ações coletivas para a defesa dos direitos ou interesses individuais homogêneos; III - Da ação coletiva passiva; IV - Procedimentos especiais; V - Disposições finais. A primeira parte, regulando as ações coletivas em geral, procurou dar um encadeamento lógico na estruturação dos seus capítulos, organizando-os do seguinte modo: Capítulo I - Da tutela coletiva; Capítulo II Dos pressupostos processuais e das condições da ação (com as seguintes seções: Seção I - Do órgão judiciário; Seção II - Da litispendência e da continência; Seção III - Das condições específicas da ação coletiva e legitimação ativa); Capítulo III - Da comunicação sobre os processos repetitivos, do inquérito civil e do compromisso de ajustamento de conduta; Capítulo IV - Da postulação; Capítulo V - Da prova; Capítulo VI - Do julgamento, do recurso e da coisa julgada; Capítulo VII - Das obrigações específicas; Capítulo VIII - Da liquidação e da execução; Capítulo IX - Do cadastro nacional de processos coletivos e do fundo de direitos difusos, coletivos e individuais homogêneos. A Parte IV, destinada aos procedimentos especiais foi desmembrada em quatro capítulos: I - Do mandado de segurança coletivo; II - Do mandado de injunção coletivo; III - Da ação popular; IV - Da ação de improbidade administrativa.

A boa construção sistemática do pretenso Código Brasileiro de Processos Coletivos mostra-se importante não apenas sob o prisma do aspecto formal, mas, também, por exemplo, como a da competência e da legitimação devem estar dispostas em parte geral destinadas às ações coletivas em geral, como se procurou fazer na versão elaborada pelos Programas de Pós-Graduação da UERJ e UNESA. Na versão oficial encaminhada inicialmente ao
} 
Haveria ação coletiva passiva quando um agrupamento humano fosse colocado como sujeito passivo de uma relação jurídica afirmada na petição inicial. Formula-se demanda contra uma dada coletividade. Os direitos afirmados pelo autor da demanda coletiva podem ser individuais ou coletivos (lato sensu) - nessa última hipótese, há uma ação duplamente coletiva, pois o conflito de interesses envolve duas comunidades distintas. A demanda, como já verificado supra, seria dirigida contra uma coletividade, sujeita de uma situação jurídica passiva (um dever ou um estado de sujeição, por exemplo). (DIDIER; MOUTA, 2009, p. 211-212).

\section{CONCLUSÃO}

A reprodução das iniciativas de restrição ao manuseio das ações coletivas, a involução da legislação processual brasileira em matéria de proteção processual do consumidor com a manutenção, por exemplo, de dispositivos refratários ao alcance erga omnes da coisa julgada coletiva (Art.16 da lei LACP), convite impróprio à habilitação prematura de consumidores individuais nas ações relativas aos interesses individuais homogêneos antes do resultado da ação (Art.94 do CDC), impossibilidade de fruição direta e imediata dos efeitos concretos das sentenças coletivas ante à limitação, hoje muito questionável, da destinação forçada dos recursos obtidos com a condenação judicial ao Fundo de Reparação dos Direitos Difusos e Coletivos, previsto no artigo 13 da LACP, tudo acaba por sugerir uma reflexão mais profunda sobre a maior influência de grandes grupos econômicos no contexto político-decisório das relações de consumo, mesmo diante de uma lógica de autoridade política compartilhada no âmbito da Política Nacional das Relações de Consumo.

Em dezembro de 2015, a comunidade jurídica se viu surpreendida com o arquivamento sumário do Projeto de Lei 282/2012, que tratava do aperfeiçoamento da legislação processual coletiva em matéria de consumo, mesmo após um produtivo debate político por meio de audiências públicas que amadureceu o projeto de acordo com os anseios sociais da sociedade pós-moderna de consumo e produziria profundas inovações em favor da proteção consumerista, corrigindo muitas das distorções referidas no parágrafo anterior.

Para agravar a situação, o consumidor brasileiro, hoje, esbarra na proliferação de decisões judiciais problemáticas em relação ao alcance da tutela coletiva, seja pela negativa ao

Ministério da Justiça, contudo, as regras pertinentes à competência e à legitimação encontram-se inseridas no capítulo destinado à ação coletiva ativa, quando, na verdade, dizem respeito, também às ações coletivas passivas. (DIDIER; MOUTA, 2009, p. 91). 
reconhecimento da figura do dano moral coletivo e do próprio estado de danosidade que paira sobre a sociedade de consumo e obrigaria o judiciário, por exemplo, a elastecer o alcance da responsabilidade civil e reconhecer o dever geral e abstrato de precaução do empresário, a negativa quanto à legitimação ativa da Defensoria Pública para a tutela dos interesses individuais homogêneos, dentre outras decisões problemáticas com repercussão em toda a cadeia de consumo e etc.

E ainda mais perigosa é a possibilidade de se importar do direito norte-americano a figura da ação coletiva passiva (Defendant class action), que impactaria diretamente a mobilidade cívica e o poder de ação da sociedade de consumo brasileira, através de suas associações representativas e também dos próprios legitimados oficiais, que, se já não conseguem instrumentalizar as demandas coletivas no polo ativo na mesma velocidade que a massificação dos conflitos ocorre, quiçá se forem impedidos de agir, a priori, quando instados a se defender no polo passivo de ações propostas por grandes conglomerados econômicos ou mesmo pelo próprio Estado, através de eventuais acordos políticos espúrios em detrimento do interesse geral dos consumidores.

Nesse sentido, revela-se mais que prudente e conveniente utilizar a experiência norteamericana para confrontar e melhor interpretar alguns movimentos legislativos e judiciais refratários a expansão da tutela processual coletiva do consumidor no Brasil, de modo que se possa ampliar a perspectiva do debate acerca da proteção consumerista para sua dimensão transindividual, evidenciando suas virtudes e benefícios para o mercado de consumo, melhor qualificando e profissionalizando a atuação dos legitimados extraordinários e insistindo no aperfeiçoamento do sistema coletivo como um todo, tanto no âmbito judicial, mas também em frentes extrajudiciais, como no caso da ocupação dos espaços de cidadania instrumental da Política Nacional das Relações de Consumo ${ }^{6}$, como por exemplo através das audiências públicas, conselhos e convenções coletivas de consumo.

Deve-se, por fim, romper com a tradição pulverizada das ações individuais, que não apenas inflam um Judiciário há muito cambaleante no processamento das mesmas, o que acaba por reforçar práticas abusivas do fornecedor pela certeza e economicidade de que agir na infra legalidade compensa. Em outras palavras, os fornecedores atingem os consumidores em proporções massificadas, mas são condenados em demandas individuais, cujos efeitos

\footnotetext{
${ }^{6}$ Cf.: VERBICARO, Dennis. Espaços Políticos de Deliberação no âmbito da Política Nacional das Relações de Consumo e seus desafios. 2016. Trabalho apresentado no V Encontro Internacional do CONPEDI, Montevidéu, 2016.
} 
econômicos e pedagógicos são infinitamente menores em comparação com os malefícios causados à coletividade.

\section{REFERÊNCIAS BIBLIOGRÁFICAS}

ALMEIDA, Gregório Assagra. Direito processual coletivo brasileiro: um novo ramo do direito processual. São Paulo: Saraiva, 2003.

ÁLVAREZ, Carlos Lasarte. Manual sobre protección de consumidores y usuários. Madrid: Editorial Dykinson, 2010.

BUJOSA VADELL, Lorenzo. La protección jurisdicional de los intereses de grupo. Barcelona: José María Bosh Editor, S.A, 1995.

CARPENA, Heloísa. S.O.S Ações Civis Públicas. Revista de Direito do Consumidor, São Paulo, ano 25, vol. 104, mar.-abr./2016.

DIDIER JÚNIOR, Fredie; MOUTA, José Henrique (coord). Tutela Jurisdicional Coletiva. Salvador: JusPodium, 2009.

DIDIER JÚNIOR, Fredie; ZANETI JÚNIOR, Hermes. Curso de Direito Processual Civil: processo coletivo. 4.ed. Salvador: JusPodium, 2009.

DINAMARCO, Pedro. Competência, conexão e prevenção nas ações coletivas. In: MILARÉ, Edis (coord.). A ação civil pública após 20 anos: efetividade e desafios. São Paulo: Revista dos Tribunais. 2005.

GIDI, Antônio. A Class Action como Instrumento de Tutela Coletiva dos Direitos: as ações coletivas em uma perspectiva comparada. São Paulo: Revista dos Tribunais, 2007.

LENZA, Pedro. Teoria geral da ação civil pública. São Paulo: Revista dos Tribunais, 2003.

MAZILLI, Hugo Nigro. A defesa dos interesses difusos em juízo. 9.ed. São Paulo: Saraiva, 1997.

NEGRÃO, Ricardo. Ações coletivas: enfoque sobre a legitimidade ativa. São Paulo: Liv. e Ed. Universitária de Direito, 2004.

VERBICARO, Dennis. Consumo e Cidadania. In: DIAS, Jean Carlos, KLAUTAU, Paulo (org.) Direitos Fundamentais, Teoria do Direito e Sustentabilidade. Rio de Janeiro: Forense; São Paulo: Método, 2009.

VERBICARO, Dennis. Espaços Políticos de Deliberação no âmbito da Política Nacional das Relações de Consumo e seus desafios. 2016. Trabalho apresentado no V Encontro Internacional do CONPEDI, Montevidéu, 2016. 